\title{
Effects of rainfall characteristics on the stability of tropical residual soil slope
}

\author{
Harianto Rahardjo ${ }^{1, a}$, Alfrendo Satyanaga ${ }^{1}$, Eng Choon Leong ${ }^{1}$ \\ ${ }^{1}$ School of Civil and Environmental Engineering, Nanyang Technological University, 50 Nanyang Avenue, Singapore
}

\begin{abstract}
Global climate change has a significant impact on rainfall characteristics, sea water level and groundwater table. Changes in rainfall characteristics may affect stability of slopes and have severe impacts on sustainable urban living. Information on the intensity, frequency and duration of rainfall is often required by geotechnical engineers for performing slope stability analyses. Many seepage analyses are commonly performed using the most extreme rainfall possible which is uneconomical in designing a slope repair or slope failure preventive measure. In this study, the historical rainfall data were analyzed and investigated to understand the characteristics of rainfall in Singapore. The frequency distribution method was used to estimate future rainfall characteristics in Singapore. New intensityduration-frequency (IDF) curves for rainfall in Singapore were developed for six different durations (10, 20, $30 \mathrm{~min}$ and 1,2 and $24 \mathrm{~h}$ ) and six frequencies $(2,5,10,25,50$ and 100 years). The new IDF curves were used in the seepage and slope stability analyses to determine the variation of factor of safety of residual soil slopes under different rainfall intensities in Singapore.
\end{abstract}

\section{Introduction}

Climate change has a significant effect on the statistical distribution of weather patterns over periods of time ranging from decades to millions of years. The study by Stern [1] showed that climate change affects many factors, such as, increase in groundwater table, ice melting, ecosystems, intense rainfall, high temperature, strong wind and floods. Among all factors, rainfall is the main factor that affects slope stability around the world. Previous studies indicated that rainfall events have become more intense in a number of countries, i.e. United States [2], Canada [3], Australia [4], South Africa [5], United Kingdom [6] and Europe [7]. Zhai et al. [8] reported increasing trends in daily extreme rainfalls in western China, and also parts of southwestern and southern China using the data from 1951 to 2000. Fujibe [9] found significant upward trends in heavy daily rainfalls in Japan using the data from 1901 to 2006. Groisman et al. [10] found an upward trend in the number of days with heavy rainfalls (greater than 99.7 percentile) in south eastern Australia. Gallant et al. [11] investigated rainfall trends including heavy rainfall events (95th and 99th percentiles) over two periods (i.e. 1910-2005 and 1951-2005) in southwest and east of Australia. The study by Rahardjo et al. [12] indicated that Singapore experienced the third highest amount of rainfall for one day $(366 \mathrm{~mm})$ in 75 years.
Rainfall characteristics are often used to design waterrelated structures. Reviewing and updating rainfall characteristics (i.e. Intensity-Duration-Frequency (IDF) curves) for future climate scenarios is necessary [13]. Studies on the rainfall IDF curves are important to prevent flooding and rainfall-induced slope failures. Some research works have been carried out to evaluate extreme rainfall data for different return periods and durations. Endreny and Imbeah [14] used two separate rainfall data sets in the country of Ghana with two different probability distribution frequency analysis methods to estimate IDF parameters. The results indicated that it is essential to combine meteorological and tropical rainfall measuring mission (TRMM) satellite data for IDF generation in Ghana. Madsen et al. [15] used a regional model for estimation of extreme rainfall characteristics in Denmark and updated the regional model with data from the augmented rain database for the period (1997-2005). Their studies indicated a typical annual increase of $10 \%$ in rainfall intensity with durations between 30 minutes and 3 hours (for 10 years return periods) which is applicable for most urban drainage designs.

Many researchers have developed various formulae for design storm based on the construction of IDF curves. Chen [16] derived a generalized IDF formula for any location in the United States using three basic rainfall depths, that is, R110 ( $1 \mathrm{~h}, 10$-year rainfall depth), R2410 (24 h, 10-year rainfall depth), and R1100 (1 h, 100-year rainfall depth). Pao-Shan [17] developed regional Intensity-duration-frequency (IDF) formulas based on

\footnotetext{
a Corresponding author: author@e-mail.org
} 
the scaling theory for sites without rain gauges. Forty-six recording rain gauges over northern Taiwan provide the data set for analysis. Three homogeneous regions were classified by different scaling regimes and regional IDF scaling formulas were developed in each region.

Toll et al. [18], Alonso et al. [19] and Rahardjo et al. [20] observed that rainfall-induced slope failures commonly occurred around the world, especially in areas with tropical climatic conditions like Singapore. Therefore, analyses of rainwater infiltration into slopes in many geotechnical and geoenvironmental applications, such as: embankment and landfill cover system become a very important topic of study. Most of these constructions are located above a thick unsaturated zone above a deep groundwater table $[21,22]$. The rate of water infiltration into slope is governed by permeability of the unsaturated zone above the groundwater table. As a result, changes in negative pore-water pressure or soil suction and shear strength of unsaturated soil are a function of water content [23].

In this study, the frequency distribution method (Gumbel method) was used to develop a new IDF curve for rainfall design in Singapore for six different durations $(10,20,30 \mathrm{~min}$ and 1,2 and $24 \mathrm{~h})$ and six frequency periods $(2,5,10,25,50$ and 100 years). The new IDF curve was used in the seepage and slope stability analyses to determine the variation of factor of safety of residual soil slopes under different rainfall intensities in Singapore.

\section{Rainfall Conditions in Singapore}

Climate in Singapore is characterized by uniform temperature and pressure, high humidity and particularly, abundant rainfalls. Based on National Environmental Agency of Singapore data, the climatic condition in Singapore is divided into two main seasons, the wetter Northeast Monsoon season from December to May and the drier Southwest Monsoon season from June to November. Maximum rainfall is usually observed between December and January, whereas June is noted as the driest month [24]. The annual extreme values of precipitation for six different recorded durations, namely: 10, 20, $30 \mathrm{~min}$ and 1, 2, $24 \mathrm{~h}$ have been extracted from historical rainfall records of Singapore island for the period from 1985 to 2010. Meteorological services Singapore has a network of meteorological stations which provide real-time observations across Singapore. There are over 60 automatic weather stations which are complemented with the electronic tipping bucket rain gauges across the island. The analyses of rainfall in this paper utilized rainfall data from 15 rainfall stations island-wide as shown in Figure 1 [25].

\section{Intensity-Duration-Frequency-Curve}

Intensity-duration-frequency (IDF) curves are a tool to relate rainfall and its frequency. The IDF curve is commonly used to obtain "design rainfall" for different water system projects. Chow et al. [26] and Singh [27] suggested three steps in the estimation of IDF curves. The first step included a best fitting function to each group comprising the data for a specific duration. In the second step, the new rainfall intensities for each duration and a set of selected return periods (e.g. 2, 5, 10, 25, 50, 100 years, etc.) were estimated. This was performed by using the best fitting functions of the first step. In the third step, the final IDF relationship could be obtained in two different ways: either (a) for each selected return period the rainfall intensities were computed and a graphical relationship of intensity and duration for different return periods was established, or (b) the rainfall intensity was functionally related to the rainfall duration and the return period using mathematical and regression analyses to derive such equation.

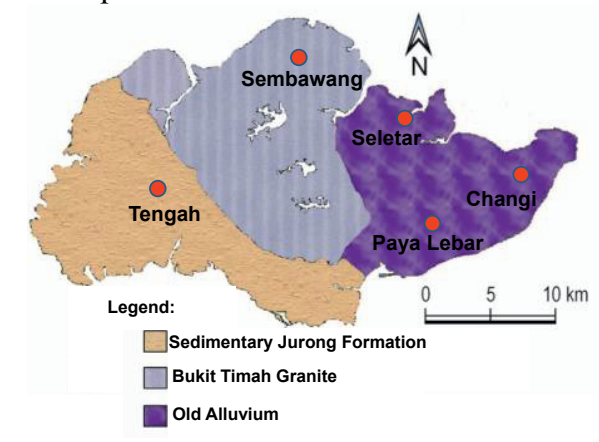

Figure 1. Location of rainfall station across Singapore island

The frequency distribution method, namely Gumbel distribution function [28] was used in this study. Gumbel method was the most widely used distribution function for analyses of IDF curve owing to its suitability for modelling maxima. The annual maximum rainfall depth (P) for different durations, $\mathrm{t}_{\mathrm{d}}(5 \mathrm{~min}, 10 \mathrm{~min}, 30 \mathrm{~min}, 60$ $\mathrm{min}, 120 \mathrm{~min}$ and $600 \mathrm{~min}$ ) was tabulated to obtain the average (Pave) and standard deviation (S) of the maximum rainfall depth for periods between 1985 and 2010. These variables were required in computing rainfall intensity (IT) for specific frequency (return) period using frequency distribution methods. Annual historical maximum rainfall depth, $\mathrm{P}$ (in $\mathrm{mm}$ ) values for the above six durations were extracted from 5 main meteorological stations in Singapore and summarized in Table 1. The selection of maximum rainfall for each duration in Table 1 was carried out based on the "continuous rainfall" method. If the duration of particular rainfall from meteorological data was less than the designated duration (i.e. $10 \mathrm{~min}, 20 \mathrm{~min}, 30 \mathrm{~min}$, etc) in the paper, the rainfall was not used in this study.

Table 1. Annual maximum rainfall (P) from 5 different rainfall stations in Singapore

\begin{tabular}{|c|c|c|c|c|c|c|}
\hline Year & \multicolumn{7}{|c|}{$\mathrm{P}(\mathrm{mm})$} \\
\cline { 2 - 7 } & $\begin{array}{c}5 \\
\min \end{array}$ & $\begin{array}{c}10 \\
\min \end{array}$ & $\begin{array}{c}30 \\
\min \end{array}$ & $\begin{array}{c}60 \\
\min \end{array}$ & $\begin{array}{c}120 \\
\text { min }\end{array}$ & $\begin{array}{c}600 \\
\text { min }\end{array}$ \\
\hline 1985 & 24 & 103 & 123 & 101 & 250 & 10 \\
\hline 1990 & 58 & 128 & 129 & 115 & 99 & 107 \\
\hline 1995 & 138 & 95 & 135 & 124 & 22 & 452 \\
\hline 2000 & 88 & 66 & 126 & 117 & 28 & 11 \\
\hline 2005 & 74 & 96 & 122 & 137 & 48 & 106 \\
\hline 2010 & 26 & 80 & 147 & 106 & 34 & 111 \\
\hline $\mathbf{P}_{\text {ave }}$ & $\mathbf{6 8}$ & $\mathbf{9 5}$ & $\mathbf{1 3 0}$ & $\mathbf{1 1 7}$ & $\mathbf{8 0}$ & $\mathbf{1 3 3}$ \\
\hline $\mathbf{S}$ & $\mathbf{4 3}$ & $\mathbf{2 1}$ & $\mathbf{9}$ & $\mathbf{1 3}$ & $\mathbf{8 8}$ & $\mathbf{1 6 3}$ \\
\hline
\end{tabular}


The first step in the construction of IDF curves is best fitting certain function to the maximum rainfall amounts for a number of fixed durations. Then, the relationships of the rainfall intensity for any duration and return period can be derived. Figure 2 shows the original IDF curves of Singapore for $2,5,10,25,50$ and 100 years return periods. The IDF curves show similarity with the upper half portion of the sigmoidal curve. Therefore, a logistic function was adopted for best fitting the IDF curve of Singapore. The proposed equation for best fitting IDF curve of Singapore is shown in Equation 1. The parameters of equation 1 used in best fitting the original IDF curve of Singapore are summarized in Table 2.

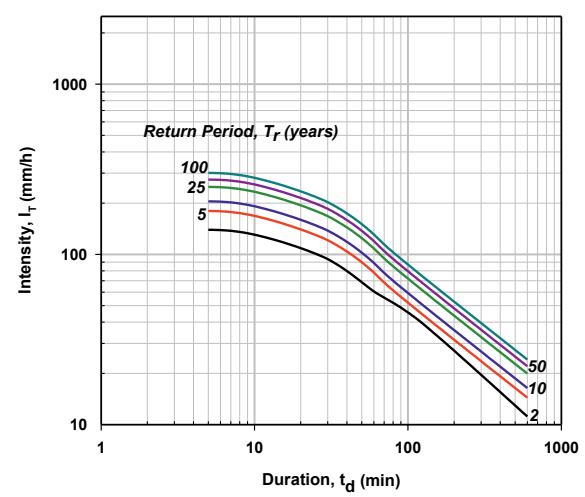

Figure 2. Original intensity-duration-frequency curves of Singapore

$$
I_{T}=\left[\frac{I_{t r}}{\ln \left(\exp +\left(\frac{t_{d}}{b}\right)^{c}\right)}\right]^{d}
$$

Note:

$\mathrm{I}_{\mathrm{T}} \quad=$ rainfall intensity $(\mathrm{mm} / \mathrm{h})$

$\mathrm{t}_{\mathrm{d}}=$ duration (min)

$\mathrm{I}_{\mathrm{tr}}=$ the maximum rainfall intensity at particular return period $(\mathrm{mm} / \mathrm{h})$

$\mathrm{b}$ = fitting parameter related to the bending in the IDF curve (min)

$\mathrm{c}, \mathrm{d}=$ fitting parameters related to the shape of the IDF curve

Table 2. Parameters of the proposed equation in best fitting the original IDF curve of Singapore

\begin{tabular}{|c|c|c|c|c|}
\hline $\mathrm{T}_{\mathrm{r}}$ (years) & $\mathrm{I}_{\mathrm{tr}}$ & $\mathrm{b}$ & $\mathrm{c}$ & $\mathrm{d}$ \\
\hline 2 & 139 & 32.4 & 1.48 & 1.74 \\
\hline 5 & 180 & 32.4 & 1.48 & 1.74 \\
\hline 10 & 205 & 32.4 & 1.48 & 1.74 \\
\hline 25 & 249 & 32.4 & 1.48 & 1.74 \\
\hline 50 & 275 & 32.4 & 1.48 & 1.74 \\
\hline 100 & 301 & 32.4 & 1.48 & 1.74 \\
\hline
\end{tabular}

The second step in the construction of IDF curves is the estimation of a new rainfall intensity for different durations and return periods in Singapore. In this method, the frequency of rainfall, PT (mm) for any rainfall duration $t_{d}$ (hour) with specified return period $\operatorname{Tr}$ (years) is computed using Equation 2 [29].

$$
P_{T}=P_{a v e}+K_{T} S
$$

where:

$\mathrm{P}_{\mathrm{ave}}=$ the average of maximum rainfall depth which can be calculated using Equation 3.

$$
P_{\text {ave }}=\frac{\sum_{i=1}^{n} P_{i}}{n}
$$

where $\mathrm{P}_{\mathrm{i}}$ is the maximum rainfall depth for particular year and for certain rainfall duration $(\mathrm{mm})$ and $\mathrm{n}$ is the number of years, respectively.

$\mathrm{S}=$ the standard deviation of maximum rainfall depth which can be calculated using Equation 4.

$$
S=\sqrt{\frac{1}{n} \sum_{i=1}^{n}\left(P_{i}-P_{a v e}\right)^{2}}
$$

$\mathrm{K}_{\mathrm{T}}$ is Gumbel frequency factor which can be calculated using Equation 5.

$$
K_{T}=-\frac{\sqrt{6}}{\pi}\left\{0.5772+\ln \left[\ln \left(\frac{T_{r}}{T_{r}-1}\right)\right]\right\}
$$

Then, the rainfall intensity, $\mathrm{I}_{\mathrm{T}}(\mathrm{mm} / \mathrm{h})$ for return period $\mathrm{T}_{\mathrm{r}}$ can be obtained from Equation 6 .

$$
I_{T}=\frac{P_{T}}{t_{d}}
$$

where $t_{d}$ is duration in hour $(1 / 6,1 / 3,1 / 2,1,2,24 \mathrm{~h})$.

The calculated frequency and intensities of rainfall for different durations and return periods based on the historical annual maximum rainfall from 1985 to 2010 in Singapore are indicated using dotted symbols in Figures 3 and 4 . The final step in the construction of IDF curves is best fitting the calculated new rainfall intensities using Equation 1 as proposed in this study. The best fitted line for the new IDF curves of Singapore are shown in Figures 3 and 4 . The parameters of Equation 1 in describing the new IDF curve are summarized in Table 3.

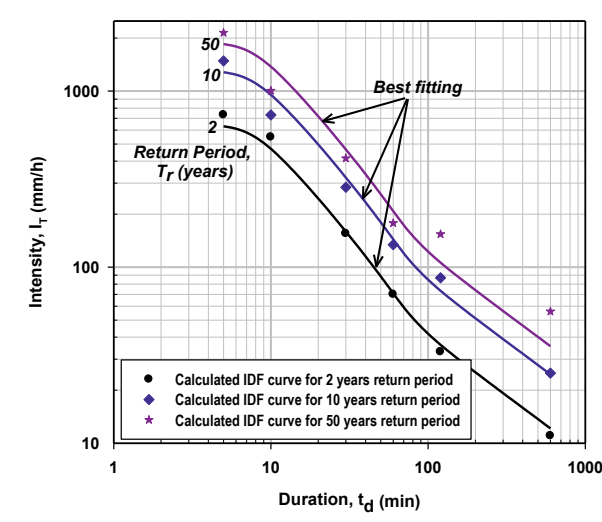

Figure 3. Modified intensity-duration-frequency curve of Singapore for 2, 10 and 50 years return periods as calculated using Gumbel method 


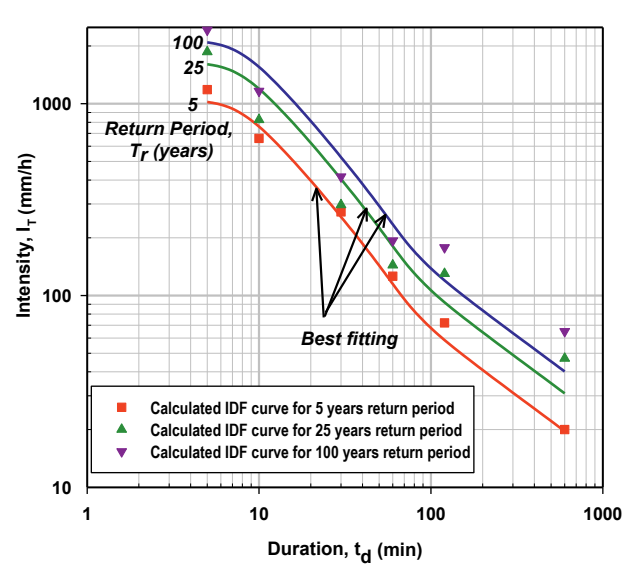

Figure 4. Modified intensity-duration-frequency curve of Singapore for 5, 25 and 100 years return periods as calculated using Gumbel method

Table 3. Parameters of Equation 1 in describing the new IDF

\begin{tabular}{|c|c|c|c|c|}
\hline \multicolumn{5}{|c|}{ curves of Singapore } \\
\hline $\mathrm{T}_{\mathrm{r}}$ (years) & $\mathrm{I}_{\mathrm{tr}}$ & $\mathrm{b}$ & $\mathrm{c}$ & $\mathrm{d}$ \\
\hline 2 & 631 & 12 & 1.8 & 2.1 \\
\hline 5 & 1020 & 12 & 1.8 & 2.1 \\
\hline 10 & 1279 & 12 & 1.8 & 2.1 \\
\hline 25 & 1606 & 12 & 1.8 & 2.1 \\
\hline 50 & 1848 & 12 & 1.8 & 2.1 \\
\hline 100 & 2088 & 12 & 1.8 & 2.1 \\
\hline
\end{tabular}

Parameters $I_{\text {tr }}$ in Table 3 indicated that the rainfall intensity for short duration of rainfall $(5,10,20$ minutes) in the new IDF curves were much higher than the one in the original IDF curves of Singapore for all return periods. The same values of parameters $b, c$ and $d$ in Table 3 show that the new IDF curves have the same shape for different return periods which are also observed in Table 2. The lower $b$ value in the new IDF curve (12 min) as compared to that in the original IDF curve (32.4 min) shows that the increase in the rainfall intensity occurs in the shorter duration of rainfall. In the new IDF curve, the rainfall intensity has increased significantly for durations higher than 12 minutes whereas in the original IDF curve, the rainfall intensity only increases significantly for durations higher than 32.4 minutes. The higher values of parameters $\mathrm{c}$ and $\mathrm{d}$ in Table 3 as compared to those in Table 2 indicate that the new IDF curve is steeper than the original IDF curve. As a result, the rate of increase in rainfall intensity in the new IDF curve is higher than that in original IDF curve.

\section{Seepage and Slope Stability Analysis}

In this paper, numerical analyses were carried out to observe the variations of factor of safety under different frequencies of rainfall (i.e. 30 minutes and 10 hours) for 50 year return periods. Rainfall frequency of 30 minutes was selected to represent short duration of rainfall $(\leq 60$ minutes) whereas rainfall frequency of 10 hours was selected to represent long duration of rainfall $(>60$ minutes). Transient seepage analyses were conducted using the finite element software Seep/W (Geoslope International Ltd., 2007a) and slope stability analyses were conducted using Slope/W (Geoslope International Ltd., 2007b). Based on the original IDF curve, rainfall intensities of $22 \mathrm{~mm} / \mathrm{h}$ and $185 \mathrm{~mm} / \mathrm{h}$ were observed in conjunction with rainfall durations of 10 hours and 30 minutes, respectively. Based on the new IDF curve, rainfall intensities of $36 \mathrm{~mm} / \mathrm{h}$ and $465 \mathrm{~mm} / \mathrm{h}$ were observed in conjunction with rainfall durations of 10 hours and 30 minutes, respectively. Therefore, four cases of seepage and stability analyses were carried out in this study (Table 4). Case no 1 included numerical analyses of residual soil slope under $22 \mathrm{~mm} / \mathrm{h}$ of rainfall for 10 hours. Case no 2 included numerical analyses of residual soil slope under $36 \mathrm{~mm} / \mathrm{h}$ of rainfall for 10 hours. Case no 3 included numerical analyses of residual soil slope under $185 \mathrm{~mm} / \mathrm{h}$ of rainfall for 30 minutes. Case no 4 included numerical analyses of residual soil slope under $465 \mathrm{~mm} / \mathrm{h}$ of rainfall for 30 minutes.

Table 4. Case study for numerical analyses in this study

\begin{tabular}{|c|c|c|}
\hline Case & $\begin{array}{c}\text { Rainfall intensity } \\
(\mathrm{mm} / \mathrm{h})\end{array}$ & $\begin{array}{c}\text { Duration } \\
(\mathrm{min})\end{array}$ \\
\hline 1 & 22 & 600 \\
\hline 2 & 36 & 600 \\
\hline 3 & 185 & 30 \\
\hline 4 & 465 & 30 \\
\hline
\end{tabular}

The initial condition for all cases was taken as hydrostatic pore-water pressure conditions. The finite element model and the boundary conditions for all cases were similar as shown in Figure 5. The initial position of groundwater table $(6 \mathrm{~m}$ and $1 \mathrm{~m}$ depths below the crest and the toe of the slope, respectively) as well as the height $(15 \mathrm{~m})$ and the angle $\left(27^{\circ}\right)$ of the slope for all cases analyzed in this study were obtained from Rahardjo et al. (2010) to represent typical position of groundwater table and slope geometry of residual soil slopes in Singapore. Soil-water characteristic curve (SWCC) and permeability function used in this study were extracted from Satyanaga et al. (2014) for residual soil slopes from Bukit Timah Granite in Singapore as presented in Figures 6 and 7, respectively.

Stability analyses of the residual soil slope were carried out by incorporating the pore-water pressures from different time increments as obtained from the seepage analyses. The factors of safety at different time increments were calculated using Bishop's simplified method of slices. The saturated and unsaturated shear strengths were incorporated in Slope/W for analyzing the stability of the residual soil slope under different rainfalls. Effective cohesion, c', effective friction angle, $\phi$ ' and rate of change in shear strength due to matric suction change, $\phi^{\mathrm{b}}$ angle used in this study were $16.5 \mathrm{kPa}$, $26^{\circ}$ and $13^{\circ}$, respectively. Figure 8 shows the variation of factor of safety of the residual soil slope under rainfall intensities of $185 \mathrm{~mm} / \mathrm{h}$ and $465 \mathrm{~mm} / \mathrm{h}$ for 30 minutes. Figure 9 shows the variation of factor of safety of the residual soil slope under rainfall intensities of $22 \mathrm{~mm} / \mathrm{h}$ and $36 \mathrm{~mm} / \mathrm{h}$ for 10 hours. 


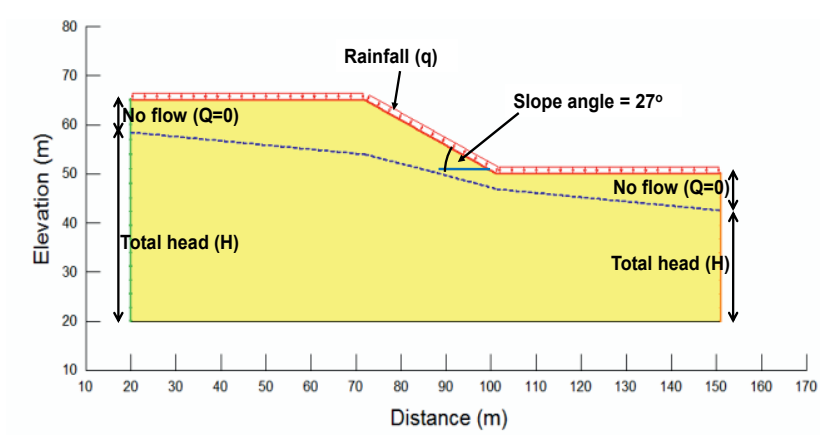

Figure 5. Slope model for seepage analyses of all cases in this study

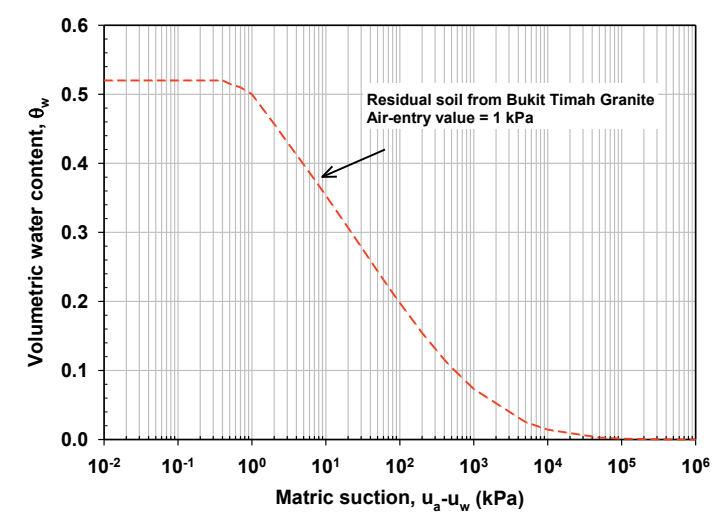

Figure 6. Soil-water characteristic curve used in this study

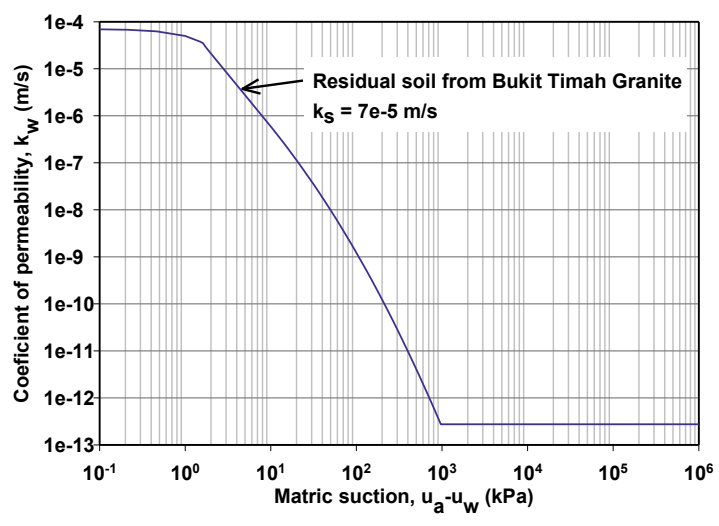

Figure 7. Permeability function used in this study

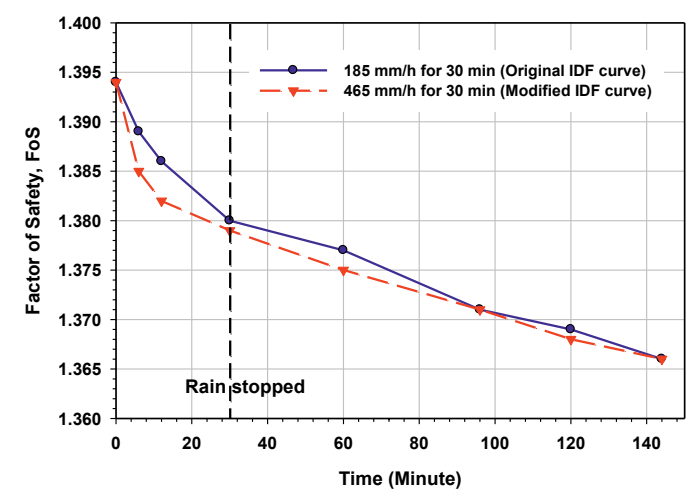

Figure 8. Variation of factor of safety for the investigated residual soil slope under 30 minutes of rainfall

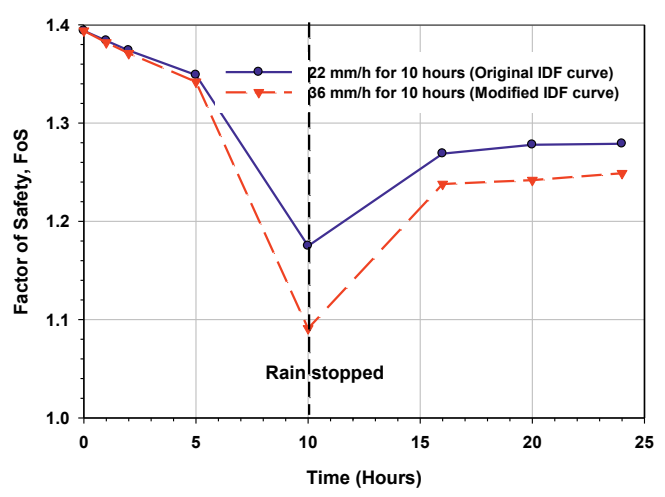

Figure 9. Variation of factor of safety for the investigated residual soil slope under 10 hours of rainfall

Comparing rainfall intensities and saturated permeability $\left(\mathrm{k}_{\mathrm{s}}\right)$ of soil used in the analyses, rainfall intensity in case 3 is lower than $\mathrm{k}_{\mathrm{s}}$ whereas rainfall intensity in case 4 is higher than $k_{s}$. However, Figure 8 shows that the variations in factor of safety with respect to time during and after rainfalls of $185 \mathrm{~mm} / \mathrm{h}$ and 465 $\mathrm{mm} / \mathrm{h}$ were similar. These could be attributed to a short duration of rainfall loading on the surface of the slope, resulting in small changes of pore-water pressures near the surface. Hence, the differences in the variations of factor of safety for residual soil slopes under rainfall intensities obtained from the original and the new IDF curves were very small. Figure 9 indicates that factor of safety of the residual soil slope decreased more significantly during rainfall of $36 \mathrm{~mm} / \mathrm{h}$ as compared to that during rainfall of $22 \mathrm{~mm} / \mathrm{h}$. These happened since the rainfall frequency was high (10 hours), resulting in the higher total rainfall and higher water flow within the soil layer under $36 \mathrm{~mm} / \mathrm{h}$ rainfall as compared to those associated with $22 \mathrm{~mm} / \mathrm{h}$ rainfall. Figure 9 also indicates that it is important to analyze the stability of the slope using the new IDF curve since the stability analyses using the new IDF curve produced a lower minimum factor of safety of the slope.

\section{Conclusions}

New IDF curves were proposed in this paper based on Gumbel distribution function. A new equation was also proposed to best fit the IDF curves of Singapore. The results of the numerical analyses indicated that the rainfall intensity from the new IDF curves generated a lower minimum factor of safety as compared to the rainfall intensities from the original IDF curve of Singapore. The study presented in this paper is limited to one soil type. Further analyses must be carried out to investigate the effect of changes in IDF curve on the factor of safety for different soil type.

\section{Acknowledgement}

The authors gratefully acknowledge the assistance of Handoko, Christopher and Zhao Yan, School of Civil and 
Environmental Engineering, NTU, Singapore during the data collections.

\section{References}

1. N. Stern. Cambridge University Press., 712 pp. (2007)

2. K.E. Kunkel. Natural Hazards, 29, pp 291-305 (2003)

3. D. Francis, H. Hengeveld. Environment Canada, (1998)

4. R. Suppiah, K.J. Hennessy. Int. J. Climatology, 18, pp 1141-1164 (1998)

5. S.J. Mason, P.R. Waylen, G.M. Mimmack, B. Rajaratnam, J.M. Harrison. Climatic Change, 41, pp 249-257 (1999)

6. T.J. Osborn, M. Hulme, P.D. Jones, T.A. Basnett. Int. J. Climatology, 20, pp 347-364. (2000)

7. E.J. Forland, H. Alexandersson, A. Drebs, I. Hamssen-Bauer, H. Vedin, O.E. Tveito. Norwegian Meteorological Institute, pp 1-55 (1998)

8. P. Zhai, X. Zhang, H. Wan, X. Pan. J. Climate, 18, pp 1096-1108 (2005)

9. F. Fujibe. Long-Term Changes in Precipitation in Japan. Journal of Disaster Research, 3(1), 51-52 (2008)

10. P.Y. Groisman, R.W. Knight, D.R. Easterling, T.R. Karl, G.C. Hegerl, V.N. Razuvaev. J. Climate, 615, 18, pp 1326-1350 (2005)

11. A.J.E. Gallant, K.J. Hennessy, J. Risbey. Australian Meteorological Magazine, 56, pp 223-239 (2007)

12. H. Rahardjo, A. Satyanaga, E.C. Leong. J. Eng. Geology, Special Issue on Unsaturated Soils: Theory and Applications, 165, pp. 133-142 (2013)

13. G. Mirhosseini, P. Srivastava, L. Stefanova. Regional Environmental Change, 13, 1, pp 25-33 (2013)

14. T.A. Endreny, N. Imbeah. J. Hydrology, 371, 1-5, 182-191 (2009)

15. H. Madsen, K. Arnbjerg-Nielsen, P.S. Mikkelsen. Atmos. Res. 92, 3, 343-349 (2009)

16. C.L. Chen. ASCE, J. Hydro. Eng. 109, 1603-1621 (1983)
17. Yu, Pao-Shan, Yang, Tao-Chang, Lin, Chin-Sheng. (2004). J. Hydro. 295, 1-4,10, 108-123.

18. D.G. Toll, H. Rahardjo, E.C. Leong. Proc., 2nd International Conf. on landslides, slope stability and the safety of infrastructure (1999)

19. E.E. Alonso, A. Gens, C.H. Delahaye. Hydrogeology J. 11, pp. 174-192 (2003)

20. H. Rahardjo, A. Satyanaga, E.C. Leong. Proc. Australia New Zealand Conference on Geomechanics "Common Ground". Brisbane, Australia. 2: 704-709 (2007)

21. J. Gasmo, K.J. Hritzuk, H. Rahardjo, E.C. Leong. Geo. Test. J. 22, 2, 128-137 (1999)

22. H. Rahardjo, A. Satyanaga, E.C. Leong. Proc. The International Seminar on Civil and Infrastructure Engineering 2008 for Environmental Sustainability. pp. 1-20 (2008)

23. D.G. Fredlund, H. Rahardjo, M.D. Fredlund. Unsaturated Soil Mechanics in Engineering Practice. 926 pp (2012)

24. H. Rahardjo, A. Satyanaga, E.C. Leong, J.-Y. Wang. Procedia Earth and Planetary Science, 9, pp. 23-43 (2014)

25. National Environment Agency Meteorological Services Data. Singapore: National Environment Agency. (2010)

26. V.T. Chow, D.R. Maidment, L.W. Mays. Applied Hydrology. (1988)

27. V.P. Sigh. Elementary Hydrology. Prentice-Hall, New Jersey (1992)

28. E.J. Gumbel. Statistics of Extremes. Columbia University Press, New York (1958)

29. E.M. Wilson. Engineering Hydrology, fourth ed. Macmillan, London (1990)

30. Geoslope International Ltd., Seep/W User's Guide for Finite Element Analysis, (2007a)

31. Geoslope International Ltd., 2007b. Slope/W User's Guide for Finite Element Analysis, (2007b)

32. H. Rahardjo, A. Satyanaga, E.C. Leong, Ng, Y.S. J. Geo. Geoenviro. Eng., ASCE. 136, 11, 1555-1564 (2010)

33. A. Satyanaga, H. Rahardjo, E-.C. Leong, Y.H. Chia, J-.Y. Wang. Proc. Int. Conf. Unsaturated Soils. (2014) 